\title{
FBG sensing for hot spot thermal monitoring in electric machinery random wound componenets
}

DOI:

10.1109/ICELMACH.2016.7732837

\section{Document Version}

Accepted author manuscript

Link to publication record in Manchester Research Explorer

\section{Citation for published version (APA):}

Mohammed, A., Durovic, S., Smith, A., \& Tshiloz, K. (2016). FBG sensing for hot spot thermal monitoring in electric machinery random wound componenets. In Electrical Machines (ICEM), 2016 XXII International Conference on https://doi.org/10.1109/ICELMACH.2016.7732837

\section{Published in:}

Electrical Machines (ICEM), 2016 XXII International Conference on

\section{Citing this paper}

Please note that where the full-text provided on Manchester Research Explorer is the Author Accepted Manuscript or Proof version this may differ from the final Published version. If citing, it is advised that you check and use the publisher's definitive version.

\section{General rights}

Copyright and moral rights for the publications made accessible in the Research Explorer are retained by the authors and/or other copyright owners and it is a condition of accessing publications that users recognise and abide by the legal requirements associated with these rights.

\section{Takedown policy}

If you believe that this document breaches copyright please refer to the University of Manchester's Takedown Procedures [http://man.ac.uk/04Y6Bo] or contact uml.scholarlycommunications@manchester.ac.uk providing relevant details, so we can investigate your claim.

\section{OPEN ACCESS}




\title{
FBG Sensing for Hot Spot Thermal Monitoring in Electric Machinery Random Wound Components
}

\author{
A. Mohammed, S. Djurović, A.C. Smith, K. Tshiloz
}

\begin{abstract}
IAbstract - This paper investigates the application of Fibre Bragg Grating sensors for thermal hot spot temperature monitoring of random wound electric coils. The paper first presents the design, installation and in-situ characterisation details of a thermal sensor used for enabling thermal monitoring in the centre of the wound coil structure, in close proximity to the thermal hot spot location. A number of thermal monitoring experiments are then undertaken on a prototype current carrying test coil under a range of controlled static and dynamic thermal conditions. It is shown that reliable, improved fidelity information on the coil's thermal status can be obtained from embedded Fibre Bragg Grating thermal sensors when compared to conventional thermal sensing solutions.
\end{abstract}

Index Terms -- Fibre Bragg grating sensors; thermal monitoring; electrical winding temperature; embedded sensing.

\section{INTRODUCTION}

$\mathrm{T}$ he majority of modern industrial systems are underpinned by effective utilisation of electric machinery to provide the required energy or motion demands. The availability of critical operational parameters of on-line machinery is essential for enabling a reliable understanding of its operational integrity and insuring its proper functioning [1]. The conventional approach to monitoring the health of electric machinery is based on continuous monitoring of vital electrical, thermal and mechanical signals and their processing to extract diagnostic indices that carry information on the development of abnormal conditions [1]-[4]. Thermal monitoring of machine wound components is especially important in this regard, as winding insulation breakdown and the resulting thermal stress have been indicated to cause as much as $40 \%$ of failures in induction machinery [4]-[6]. Reliable monitoring of winding hot spot temperature, typically located at the centre of the wound coil structure, is therefore key in facilitating improved thermal protection of operative machinery and preventing damage through undesirable extended thermal overloads.

The current practice for monitoring the thermal conditions of wound components in electric machinery is predominantly based on utilising thermocouple (TC) or resistance temperature detector (RTD) sensing solutions. These are however significantly impeded in providing hot spot thermal measurement in current carrying wound components due to inherent use of electrically conductive material in their structures as well as susceptibility to EMI effects [5]. An alternative is provided by the latest advances in fibre-optic (FO) sensing technology, whose characteristic EMI immunity, robustness, flexibility and size make it a strong

S. Djurović, A Mohammed and A.C. Smith are with the School of Electrical and Electronic Engineering at University of Manchester, Manchester M13 9PL, UK. (Anees.Mohammed@postgrad.manchester.ac.uk, Sinisa.Durovic@manchester.ac.uk, Sandy.Smith@manchester.ac.uk) candidate to deliver the required operative solutions for wound components embedded thermal monitoring in mission critical applications, despite the likely higher application cost [7].

The utilisation of Fibre-Bragg grating (FBG) sensors in electric machinery monitoring has already received attention in a number of studies, ranging from frame vibration sensing to stator core and coil surface thermal monitoring [8]-[15]. The available literature on FBG use for wound component thermal monitoring is however almost exclusively focused on applications in large generators [13]-[15], with significant slot geometries and a form wound winding configuration. The existing reports on low and medium power machinery application of FBGs assess the general potential for thermal monitoring internal to machine structure and do not consider coil embedded hot spot locations [9]. In addition, the FBG thermal sensor packaging designs used in reported studies utilise conductive materials such as stainless steel and aluminium which can impose operational challenges in electrical machinery applications.

This paper reports an experimental examination of the FBG enabled hot spot thermal monitoring in a prototype random wound current carrying coil [16]. The test coil is wound of class $\mathrm{F}$ insulated copper wire to represent the designs commonly used in conventional electric machines and test procedures for random wound $\mathrm{AC}$ electric machinery insulating material evaluation [5],[17]. The FBG sensor package is made of dielectric material for enhanced immunity in this work. The procedure of sensor installation into a random wound coil structure, its calibration and characterisation are first presented. The paper then reports the results of a range of steady-state and transient thermal experiments performed on a stand-alone current carrying prototype coil and a current carrying prototype coil wound into a low power stator core structure. The FBG sensor hot spot thermal measurements are benchmarked in tests with those obtained from conventional TC sensors placed in close proximity. The underlying aim of this work is to assess the attainable hot spot thermal monitoring performance of an FBG thermal sensor embedded in the structure of a current carrying random wound coil, as a precursor to enabling a wider application of the presented principles in operational devices.

\section{FIBRE BRAGG GRATING SENSING PRINCIPLES}

FBGs are the periodic gratings on the optical fibre core that result in a periodic modulation of its refractive index when exposed to an interference pattern of laser light [16]. The wavelengths reflected by the FBG structure will alter with the variation in the strain and/or temperature it is exposed to. With appropriate design, this phenomenon enables the grated fibre to be utilised as a mechanical or a thermal sensor. The FBG centre wavelength is given as [18]: 


$$
\lambda_{B}=2 \Lambda n_{\text {eff }}
$$

where: $\lambda_{B}$ is the Bragg (i.e. centre) wavelength, $\Lambda$ is the grating period (i.e. the spacing between successive gratings) and $\mathrm{n}_{\mathrm{eff}}$ is the effective fibre core refractive index. Any change in the fibre temperature and/or strain will give rise to a change of $n_{\text {eff }}$ and $\Lambda$, and consequently result in an alteration of the reflected wavelength. The reflected Bragg wavelength relative rate of change can be defined in terms of the existing thermal and/or mechanical excitation as [19]:

$$
\Delta \lambda_{B}=\overbrace{2\left(\Lambda \frac{d n_{e f f}}{d \varepsilon}+n_{e f} \frac{d \Lambda}{d \varepsilon}\right) \Delta \varepsilon}^{A}+\overbrace{2\left(\Lambda \frac{d n_{e f f}}{d T}+n_{e f} \frac{d \Lambda}{d T}\right) \Delta T}^{B}
$$

where: $\varepsilon$ is strain and $\mathrm{T}$ is temperature. The term $\mathrm{A}$ in (2) represents the Bragg wavelength shift caused by the strain induced elastic-optic effect. The term B describes the temperature change induced wavelength shift that arises due to thermo-optic and thermal expansion effects [18]. The reflected wavelength change due to temperature change can be expressed in terms of the fibre thermal characteristics as [20]:

$$
\Delta \lambda_{B}=\lambda_{B}(\alpha+\xi) \Delta T
$$

where: $\alpha$ is the fibre thermal expansion coefficient $(\approx 0.55 \mathrm{x}$ $\left.10^{-6} / \mathrm{K}\right)$ and $\xi$ is the fibre thermo-optic coefficient $(\approx 6.67 \mathrm{x}$ $\left.10^{-6} / \mathrm{K}\right)$ [16]. For a standard bare FBG with the Bragg wavelength of $1550 \mathrm{~nm}$ operating at ambient temperature the fibre thermal sensitivity can be evaluated to be $\approx 11 \mathrm{pm} / \mathrm{K}$.

\section{FBG SENSORS DESIGN AND EMBEDDING}

\section{A. Sensor design}

The target sensing application in this study is thermal monitoring within a random wound coil structure, in direct proximity to the coil thermal hot spot. The primary design constraints of the thermal sensing system arising from its application within a current carrying coil are the desirability for the sensing element EMI immunity and the requirement for sensing element placement in the centre of the coil structure, implanted between individual current carrying conductors. In addition, the sensing element has to be capable to function in and withstand the thermal environment characteristic of winding elements in conventional class $\mathrm{F}$ insulated electric machine designs. The bare optical fibre itself can act as a thermal sensing element, however it is extremely fragile and requires suitable packaging to ensure its mechanical integrity and isolate it from mechanical excitation, i.e. mitigate as much as possible the cross sensitivity of shifted Bragg wavelength due to temperature and strain. To achieve this, Polyetheretherketon (PEEK) tubing is used in this work to package the FBG sensing heads due to its dielectric and mechanical properties; the thermal conductivity of PEEK is $0.173 \mathrm{~W} / \mathrm{m} . \mathrm{k}$ and it can withstand operating temperatures in excess of $\approx 200^{\circ} \mathrm{C}$.

The FBG sensing configuration investigated in this paper is designed to enable thermal monitoring in two locations within the single random wound coil structure. One FBG sensing head is designed to be located at the centre point of the coil slot section (referred to as FBGS in further text), while the other is designed to be positioned at the centre of the coil end-winding section (referred to as FBGE in further text). Fig. 1 shows the schematic diagrams of the packaged sensing elements.

The total length of individual FBG probes is $1 \mathrm{~m}$. A $5 \mathrm{~mm}$ FBG head length, contained by the $5 \mathrm{~cm}$ long PEEK tubing is used in this study. These dimensions were selected to avoid any undesirable mechanical effects due to the curvature of the test coil's end winding segment. The sensing fibre is kept loose within PEEK tubing. In addition, the inner and outer diameter dimensions of the utilised PEEK tubing were chosen as $0.6 \mathrm{~mm}$ and $0.8 \mathrm{~mm}$, respectively. This was to provide a close match to the 0.56 diameter size of the test coil's copper wire and therefore facilitate easier placement and more effective thermal sensing performance of the sensor package within the random wound test coil structure. The remainder of the optic cable is tubed in Teflon for protective purposes. The FBG heads are imprinted in a polyimide coated fibre with a bandwidth of $\approx 0.374 \mathrm{~nm}$ and reflectivity of $\approx 88 \%$. The design of the curved packaged FBG terms sensor for the end winding region required particular attention to ensure the sensing head is placed at the centre position.

\section{B. Sensor installation and test coil design}

This section describes the procedure of sensor installation within a random wound test coil structure. The aim is to explain the design characteristics of the prototype FBG thermal sensor equipped coil used in this research. The random wound test coil geometry is designed according to IEEE standards for test procedures to evaluate insulating materials for random-wound AC electric machinery [17]. The motorette is purpose wound on a winding machine with a total of 117 series connected turns of class F enamelled copper wire to replicate the commercial low power induction machine stator winding design examined in this work.

The first stage of test coil design involves careful placement and positioning of FBG sensors in the centre of the IEEE prescribed motorette geometry, as illustrated in Fig. 2. The section A graph in Fig. 2 shows a detailed cross sectional view of the motorette slot section, clearly identifying the FBG thermal sensor position at the centre of the coil (FBGS). Similary, the section B detailed view in Fig. 2 illustrates the cross section of the end winding part of the prototype motorette, including the position of the FBG sensor installed in this area (FBGE). In order to accurately locate the FBG sensing packages in target positions, 50 turns were first wound before placing the FBG sensing packages in their coil centre positions and completing the winding of the remaining 67 turns. This procedure enabled the FBG thermal sensor to be located in the close proximity to the motorette centre in order to enable effective monitoring of its thermal hot spot. For the purpose of performance assessment of the embedded FBG thermal sensors with respect to a known conventional thermal sensing technology and its placement limitations, TC sensors were installed in the vicinity of the motorette embedded FBG thermal packages, as shown in Fig. 2. TC2 was attached to the coil slot section outer surface 


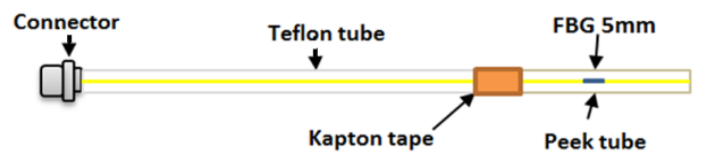

a) Coil end-winding section sensor design (FBGs)

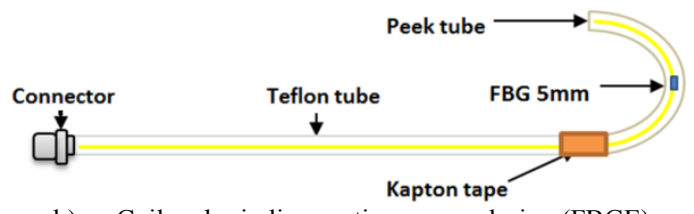

b) Coil end-winding section sensor design (FBGE) Fig. 1 : FBG thermal sensors
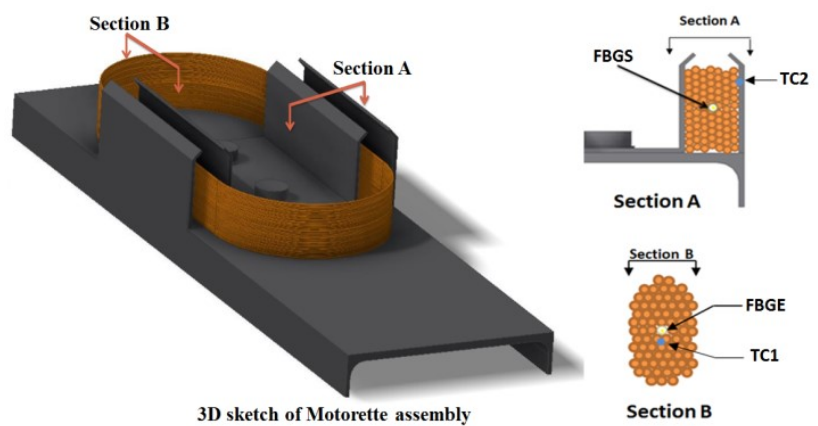

Fig. 2 : FBG sensor placement within the test motorette geometry

using Kapton tape to assess the thermal monitoring improvement potential that can be obtained from sensing in a point in the centre of the coil structure. For direct comparison of FBG versus conventional sensing performance in hot spot monitoring, TC1 was placed next to FBGE. The coil was braced with Kapton tape in places to provide further mechanical support and improve thermal contact between the test coil conductive and sensing components.

In order to enable the embedded FBG thermal monitoring evaluation in a current carrying coil wound into an $\mathrm{AC}$ machine stator geometry, the test coil design procedure described in previous text was replicated and wound into a stator core of a commercial $0.55 \mathrm{~kW}$ induction machine design, as shown in Fig. 3 including photographs of the laboratory test system. This procedure enables the assessment of the FBG sensing system's performance, installation methodology and its requirements in a typical electric machine winding setting, as an important step towards enabling future implementation of embedded FBG thermal monitoring solutions in operating random wound $\mathrm{AC}$ machinery. For this purpose the stator windings of the test stator geometry were removed and a single coil rewound with conductor dimensions and turn number (117 turns) based on the removed winding design. The test coil was wound into the core structure by first inserting one side of the coil into the appropriate slot and wedging it in place. A half of the other side of the coil was then inserted into the correct slot and kept in place to enable the installation of the FBG sensing package in the coil slot and end winding areas centre positions. After this was completed the remaining turns were placed over the sensors to complete the stator core installed FBG enabled test coil. Once the fully wound coil was in place slot wedges were inserted to compress the coil conductors and enhance the thermal contact between them and the sensor package surface. The FBG sensor placement within the prototype coil is identical to that examined for the stand-alone coil in Fig. 2. The FBG sensing elements positioning in the close proximity of the coil centre is ensured by bracing the sensor package to the initially inserted half of the coil using Kapton tape. To enable FBG sensors performance validation TCs were installed in the test coil in identical positions to those used in the stand-alone coil; TC1 was placed in the centre of the end-winding portion next to FBGE and TC2 was inserted between the coil surface and the slot insulation wall.
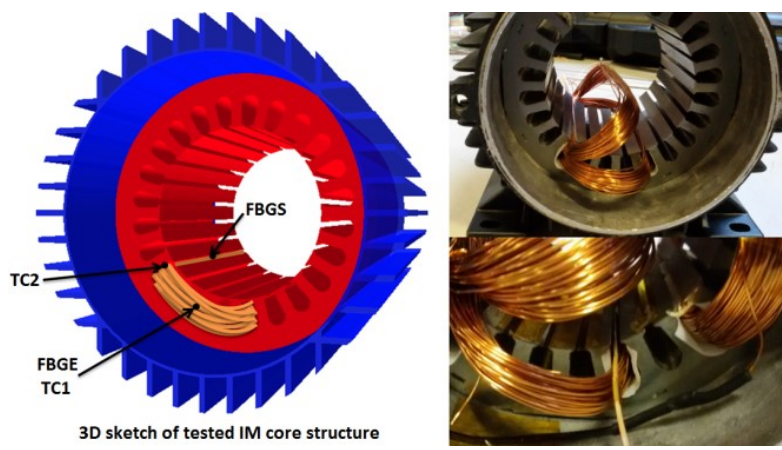

Fig. 3 : Stator core embedded FBG enabled test coil

\section{EXPERIMENTAL TEST SYSTEM}

The experimental setup for calibration and characterisation of the test coil embedded FBG sensing system utilises a controlled thermal chamber to isolate the coil containing the characterised sensors and expose it to a desired, controlled steady-state thermal stress level. A photograph of the experimental arrangement used for embedded sensor calibration and characterisation is shown in Fig. 4a. The reference temperature within the thermal chamber was read by the chamber in-built thermal sensors and an additional FLUKE $\mathrm{K}$ type thermometer placed inside the chamber and used for temperature measurement control.

The FBG sensors are illuminated by a commercial SmartScan interrogator system enabling dynamic measurement of reflected wavelengths [21]. The TCs outputs are conditioned by an NI DAQ interfaced with a personal computer executing an appropriate LabVIEW VI routine. For floating measurements a resistance circuit has been built that includes a Platinum resistance temperature detector (PT100) for cold junction temperature compensation.

The experimental test system utilised for performance investigation of FBG thermal sensing embedded in a current carrying coil is shown in Fig. 4b. A programmable DC power supply was used to inject the desired current level into the prototype coil under test. This enabled practical emulation of a range of stationary and transient thermal conditions including dynamic thermal cycling, and thus an assessment of the coil embedded FBG thermal monitoring performance in a variety of thermal conditions representative of practical applications. The coil current was measured synchronously with temperature using the LEM 55-P current transducer and the coil embedded FBG and TC sensors. 


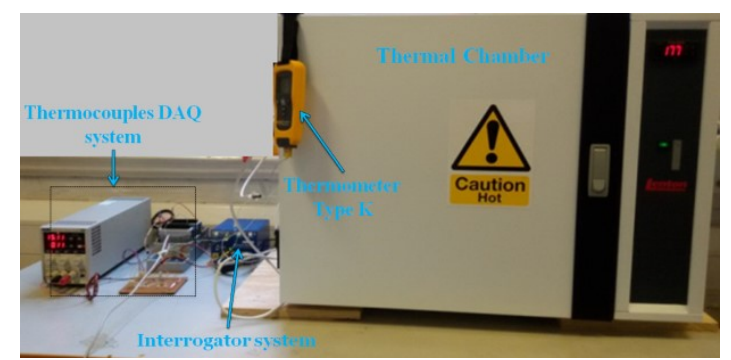

a) Experimental system setup for calibration and characterisation

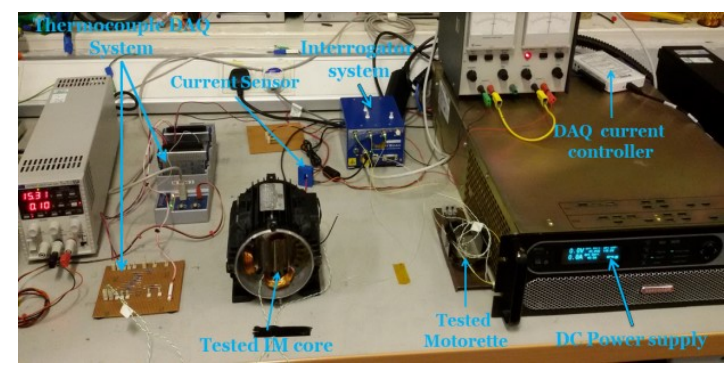

b) Experimental system setup for FBG performance assessment Figure 4: Experimental system setup

\section{EXPERIMENTAL RESULTS AND DISCUSSION}

\section{A. FBG sensors calibration and characterisation}

The results of calibration and characterisation tests of the FBG sensing system embedded in the motorette and in the stator core are reported in this section. The test data provide a detailed assessment of how the random wound coil implanted FBG sensing system may be affected by the process of sensor packaging and it's embedding into the coil structure. For this purpose an identical calibration procedure was performed on the stand-alone and the stator core wound test coils. Calibration tests were first performed on the free FBG heads before these were packaged with PEEK tubing. The obtained results (FBG Head in Fig. 5) are compared with those achieved by performing an identical calibration procedure on the packaged sensors embedded within standalone (motorette in Fig.5) and stator core wound (IMcore in Fig 5.) test coils. The calibration tests were performed in the temperature range of 20 to $160{ }^{\circ} \mathrm{C}$ to match the rated thermal range of the examined class $\mathrm{F}$ insulated wire. The temperature is regulated by the chamber controller in the tests to follow a rising sequence of $20^{\circ} \mathrm{C}$ steps. At each step the temperature was held constant for a time period sufficient to ensure the thermal equilibrium is achieved before thermal measurements were taken. The FBG wavelength and the chamber temperature values were recorded at each evaluated thermal equilibrium in the investigated temperature range.

The linearity and temperature sensitivity measured in calibration tests for free FBGs and packaged and embedded FBGS and FBGE sensors are shown in Fig. 5a and Fig. 5b respectively. The measured data indicate a reasonable linearity of coil embedded packaged FBG sensors, both having the correlation coefficient measured value higher than $\approx 0.9985$. Furthermore, the average temperature sensitivity coefficients calculated from the slope of the FBGS and FBGE calibration test data linear fits are in the ranges of 10.67 to $10.81 \mathrm{pm} /{ }^{\circ} \mathrm{C}$ and 10.95 to $11.02 \mathrm{pm} /{ }^{\circ} \mathrm{C}$, respectively. These values are close to the theoretical calculated temperature sensitivity of a bare FBG. The calibration results suggest that the procedure of FBG head packaging and insertion into a random wound coil geometry centre positions has a negligible effect on the sensor temperature sensitivity. Based on the experimentally obtained values of embedded sensor sensitivity and the utilised commercial interrogator system wavelength resolution of $1 \mathrm{pm}$, the attainable thermal measurement resolution can be calculated to be $\approx 0.11^{\circ} \mathrm{C}$ for the examined packaged sensors.

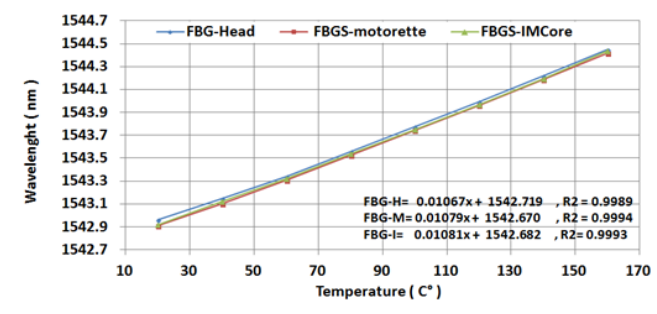

a) FBGS wavelength and temperature characteristics

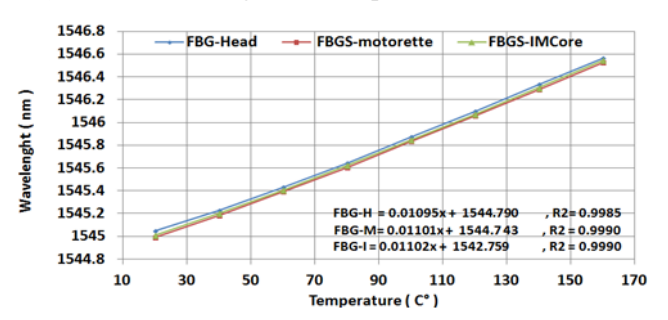

b) FBGE wavelength and temperature characteristics

Fig. 5 : FBG sensing system wavelengths - temperature characteristics

To further evaluate the embedded FBG sensor characteristics the total Bragg wavelength shift measured for the FBGS and FBGE sensors in a stand-alone and a coil wound into the stator core were compared with that of a free FBG head in the investigated temperature range. The measured data report a closely similar range of wavelength shift with a deviation of $0.028 \mathrm{pm}$ and $0.021 \mathrm{pm}$, respectively. The Bragg wavelength for both FBG sensors before and after packaging and embedding was also assessed. The measured data show an inherent Bragg wavelength offset for both FBG sensors when they are embedded within the coil structure, as illustrated by the measured reflected Bragg wavelength spectrum of FBGS and FBGE at ambient temperature shown in Fig. 6. It should be noted that the procedure of embedding the packaged FBG sensors within the coil structure results in unavoidable mechanical stress on the embedded sensor structure. The measurements in Fig.6 clearly indicate an offset in the Bragg wavelengths measured before and after the bare sensing head packaging and coil insertion procedures. While the observed offset is an inevitable artefact of the packaging and coil insertion process, it does not significantly affect the measured wavelength shift range for the examined thermal conditions.

The influence of the installation induced reflected wavelength offset on the coil embedded packaged sensor's performance is examined by comparison of the average temperature sensitivity measured in thermal tests shown in Fig. 7. The coil embedded sensors are seen to manifest a closely similar $\mathrm{pm} /{ }^{\circ} \mathrm{C}$ profile to that of a free $\mathrm{FBG}$ head in the examined temperature range. The FBG thermal measurement sensitivity increases with the monitored 
temperature increase from a value lower than $\approx 10 \mathrm{pm} /{ }^{\circ} \mathrm{C}$ to $\approx 12 \mathrm{pm} /{ }^{\circ} \mathrm{C}$. This is a typical behaviour of FBG sensors caused by the nonlinearity of the thermo-optic coefficient of the optic fibre [21]. The measured data however illustrate the importance of appropriate calibration of the coil embedded FBG sensors. A second-order polynomial quadratic fit of the measured FBG wavelength and the corresponding temperature (shown in Fig. 5) was used in this work to enable accurate thermal measurement from the recorded wavelength.

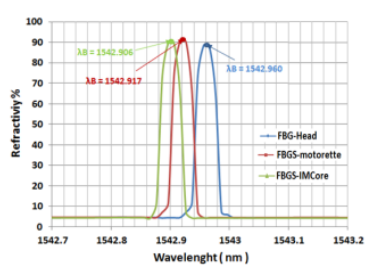

a)

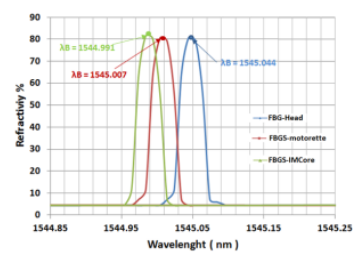

b)
Fig. 6: a) Reflected wavelength spectrum of FBGS, b) Reflected wavelength spectrum of FBGE

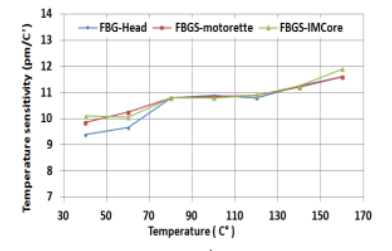

a)

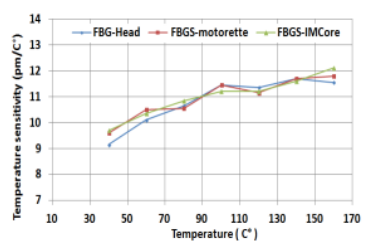

b)
Fig. 7 : a) FBGS measured temperature sensitivity, b) FBGE measured temperature sensitivity

\section{B. Motorette coil embedded FBG thermal monitoring}

This section presents the thermal hot spot monitoring results obtained from FBG sensors placed within the current carrying motorette coil. The FBG sensors thermal monitoring performance was evaluated by a number of dynamic thermal cycle tests based on the international standard for rating and performance of rotating machines, IEC 60034-1.

A continuous running duty cycle $\mathrm{S} 1$ test was first performed by injecting a DC current of $2 \mathrm{~A}$ in the motorette coil. This current level was found in tests to provide nondestructive thermal levels, that are representative of wound component thermal conditions experienced in practical systems but are below the temperature rating $\left(155^{\circ} \mathrm{C}\right)$ of the used class $\mathrm{F}$ insulation wire. The total $\mathrm{S} 1$ cycle test duration is $1500 \mathrm{sec}$ as shown in Fig. 8. The measured data clearly show a close agreement of temperature measurements between FBGS and FBGE and TC1. This is due to the fact these are exposed to same thermal environments in the centre of the current carrying motorette coil. The temperature readings respectively obtained from FBGS, FBGE and TC1 after the coil thermal equilibrium for the applied current level is reached, are $117.50{ }^{\circ} \mathrm{C}, 116.96{ }^{\circ} \mathrm{C}$ and $116.76{ }^{\circ} \mathrm{C}$, as illustrated by the detailed view inset in Fig. 8. The thermal reading obtained from the coil surface mounted TC2 however reports a slightly lower thermal level; this is expected as the thermal sensing point on the surface of the coil is affected by the surrounding ambient temperature and the temperature gradient between the coil centre temperature and that on the coil surface. The reported experimental data clearly illustrate the significance of effective thermal sensing placement and the strong potential of FBG sensors to deliver operative solutions for coil embedded hot spot monitoring. The measured temperature curves obtained from FBG sensors are significantly smoother than those acquired by TCs, with the FBG temperature measurement fluctuation lower than $0.5^{\circ} \mathrm{C}$.

In addition, an FBG thermal sensor is an indirect temperature transducer that measures temperature from the monitored reflected Bragg wavelength shift. An investigation of how the monitored wavelength behaves under dynamic thermal conditions is useful in assessing the potential of coil embedded FBG sensing for on-line condition monitoring, where reliable tracking of transient thermal processes that may originate from winding degradation is essential. For this purpose a test was undertaken on the motorette coil during which four successive thermal transients having equal duration of $300 \mathrm{sec}$ but with different, increasing thermal change rate ranging from $\approx 1-8{ }^{\circ} \mathrm{C} / \mathrm{min}$ were induced in the coil by appropriate control of the injected current. The corresponding monitored wavelength shifts for FBGS and FBGE plotted against the temperature rise measured by TC1 are shown in Fig. 9. The measured profiles clearly show that the monitored Bragg wavelength shift of both FBGS and FBGE reliably follows the temperature rise profiles under all examined temperature change rates. This suggests that coil embedded FBG thermal sensing has a good potential for delivering effective on-line thermal monitoring under transient thermal conditions.

The dynamic thermal monitoring performance of the FBG sensing system was assessed and benchmarked against a conventional thermal sensor in an intermittent periodic duty cycle S3 test, performed through appropriate modulation of the coil current. A sequence of identical thermal cycles was applied by regular switching of the DC current level from a constant 2 A to zero. The cyclic duration factor was chosen to be $60 \%$ with cycle duration of 5 min to induce a fast dynamic thermal profile that is within the thermal rating of the coil. The measured data are shown in Fig. 10. The thermal profiles recorded by the FBG and TC sensors in the motorette coil hot spots are in close agreement, with a maximum temperature difference between FBG sensors of $1.1{ }^{\circ} \mathrm{C}$ and between the FBG sensors and $\mathrm{TC} 1$ of $1.6{ }^{\circ} \mathrm{C}$. The $\mathrm{TC} 2$ measurement deviates from the hot spot thermal measurements, with a temperature difference between TC2 and TC1 of $\approx 11{ }^{\circ} \mathrm{C}$ and $\approx 3{ }^{\circ} \mathrm{C}$ for the highest and the lowest thermal levels in the considered cycle. This can be explained by the nature of the heat transfer mechanism within the coil, as the radial conduction heat transfer in the coil cross section area is faster than the natural convection heat transfer from its surface during energised time, thus creating a large temperature gradient. During cooling time no heat is generated within the coil whereas its surface has to dissipate the heat induced during the energised period. No similar effects can be observed in other thermal measurements taken in this experiment which further demonstrates the inherent advantages provided by thermal monitoring in the coil hot spot points. The reported performance of embedded FBGs shows good repeatability with no significant evidence of hysteresis at this range of temperature and dynamic change rate [21]. 


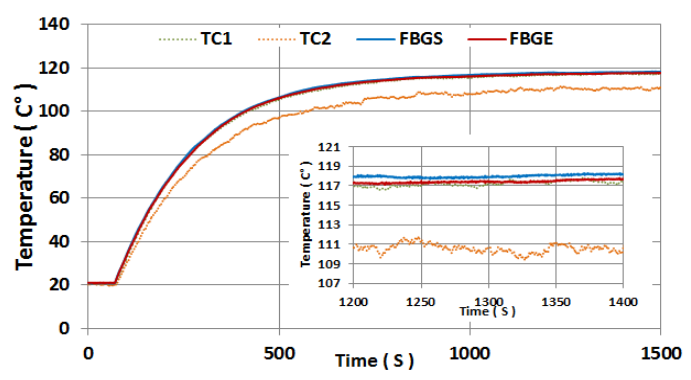

Fig. 8 : Motorette coil thermal measurements

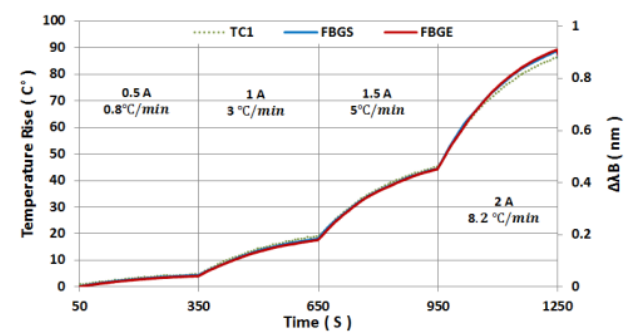

Figure 9 : Bragg wavelength shift under different temperature change rates

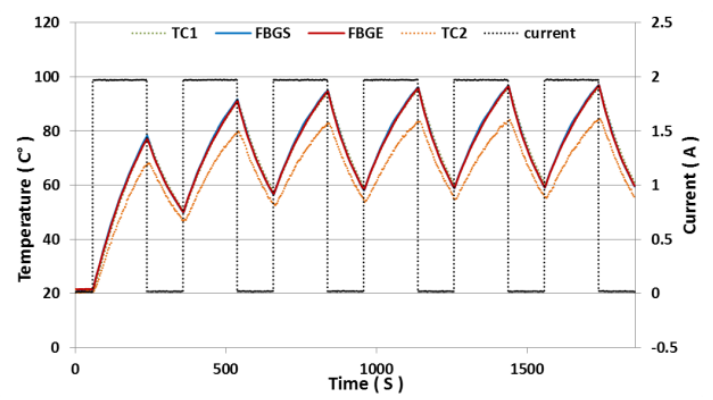

Figure 10 : FBG temperature sensors performance under thermal cycle.

\section{Stator coil embedded FBG thermal monitoring}

The performance of embedded FBG thermal sensing in a current carrying coil wound into the stator core is investigated in this section building on the analysis presented in V.B. To evaluate the sensing performance at steady-state thermal conditions a continuous duty cycle $\mathrm{S} 1$ is applied on the coil by passing constant DC current through it. Before the cycle start the test coil ambient temperature was recorded for $1 \mathrm{~min}$, a detailed view of which is shown in Fig. 11a. It can be seen that both FBGs and TCs show a close reading of ambient temperature, with a measurement difference of less than $1{ }^{\circ} \mathrm{C}$.

The measured thermal data obtained for the test cycle $\mathrm{S} 1$ is shown in Fig. 11b. A detailed view of the recorded thermal measurements once the steady-state temperature is reached is shown in Fig. 11c. Due to thermal characteristics of the stator core and frame structure the measured total cycle time is $\approx 2$ hours. The thermal traces obtained from FBGE and TC1 sensors located in the end winding hot spot show an almost identical temperature reading throughout the examined cycle duration. However, a comparison of thermal readings obtained from $\mathrm{FBGS}$ and $\mathrm{TC} 2$ shows a constant temperature difference of $\approx 3{ }^{\circ} \mathrm{C}$ during cycle time. This largely arises from the temperature gradient between the coil centre and its surface, in addition to the fact that the TC2 thermal reading is affected by the stator core temperature. More importantly, a clear difference can be observed between the thermal measurements obtained by FBGS and FBGE, measured at $\approx 6{ }^{\circ} \mathrm{C}$. This is also confirmed by the TC1 and TC2 thermal readings after accounting for the temperature difference due to the sensor placement. It should be noted that the used FBG heads are packaged separately and imprinted in separate optic cables to ensure no packaging cross effects can exist. The observed thermal readings difference can be explained by the different thermal environments that the two embedded FBG sensors are exposed to. The induced heat in the slot portion is dissipated by conduction through the slot liner to the stator core and the machine frame, which constitute a considerable thermal structure in comparison to the test coil and therefore significantly assist the heat dissipation process in the coil slot section area in the utilised experimental arrangement. In addition to axial heat conduction towards the slot section, the end winding thermal energy is largely dissipated by means of natural convection which is inherently considerably slower than the heat dissipation process in the slot portion. The results in Fig. 11 clearly demonstrate the advantages of in-situ winding temperature sensing.

Fig. 12 shows the measured thermal dynamic response curves of the stator wound test coil under an applied intermittent periodic duty cycle S3 $60 \%$. It can be observed that the four thermal sensors report closely similar profiles. The measured data however show different temperature gradients with the highest temperature reported by FBGE and TC1, which indicate the coil hot spot position in these conditions. When the test coil is de-energised the temperature decreases and the difference between individual sensors' thermal measurements is significantly reduced. The obtained FBG measurements are seen to exhibit good repeatability in monitoring the examined cyclic thermal behaviour.

To explore the embedded thermal sensing behaviour in the presence of a current carrying coil in the neighbouring slots, another 117 turn coil was wound into the stator core and placed in the slots next to those containing the test coil with FBG and TC sensors. A continuous cycle S1 test was then performed on the instrumented test coil while keeping the adjacent coil current zero. Once steady-state thermal conditions were achieved the adjacent coil is energised with an identical current level for a period of $\approx 10$ mins to investigate its thermal influence on FBG thermal records in the test coil. The FBGS and FBGE measurements and their respective difference are shown in Fig. 13. The thermal measurement difference in steady-state conditions when only the test coil is excited is measured as $\approx 6{ }^{\circ} \mathrm{C}$. Once the adjacent coil is energised $(\approx 150 \mathrm{sec})$ the measurement difference starts decreasing, with the FBGS reading clearly more affected by the heat generated by the adjacent coil than that of FBGE. The FBG thermal readings difference reduces to $\approx 2{ }^{\circ} \mathrm{C}$ at the point the adjacent coil is de-energised $(\approx 650$ $\mathrm{sec}$ ), after which it starts rising back to its original level. The reported results demonstrate that the wound coil embedded distributed FBG thermal sensing can provide high resolution information on the coil thermal conditions.

\section{CONCLUSIONS}

This paper reports a detailed investigation of the design and installation procedures and operational capabilities of FBG sensor enabled thermal hot spot temperature sensing in 


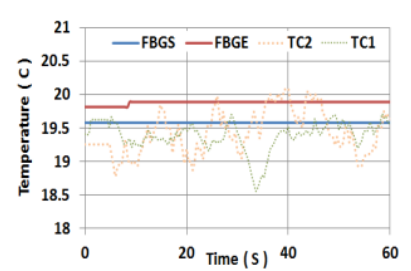

a) Ambient temperature

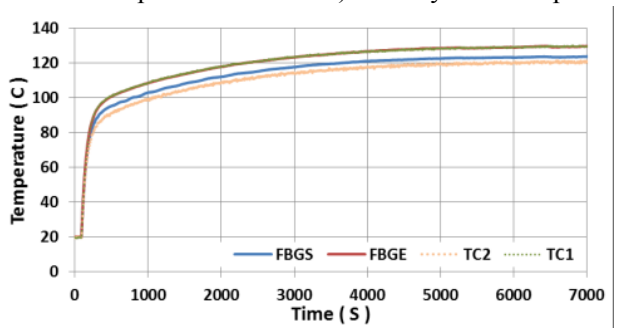

b) Temperature measurements for thermal cycle $\mathrm{S} 1$

Figure 11: Thermal measurement for a continuous thermal cycle

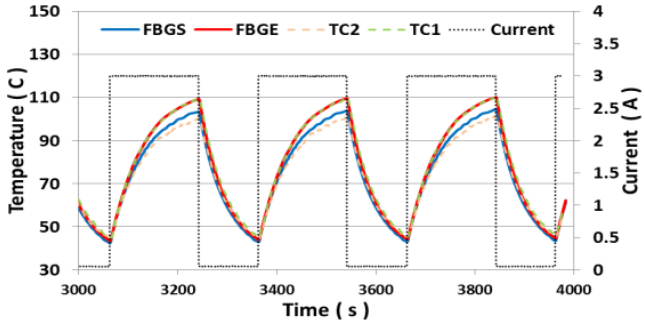

Figure 12: Thermal measurement for an intermittent periodic thermal cycle.

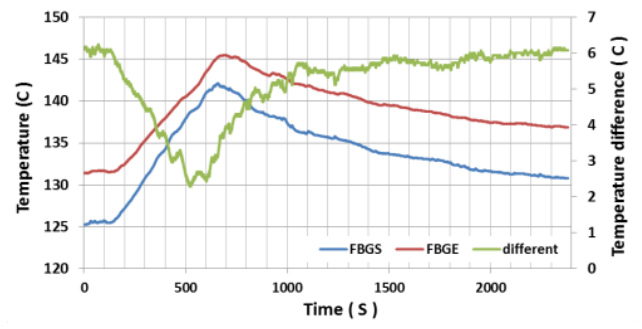

Figure 13: External thermal excitation measurements effects

random wound coils such as used in electric machinery. The current carrying coil embedded thermal monitoring performance is evaluated in a number of static and dynamic thermal experiments on a prototype test coil system in a stand-alone environment and when wound into a stator core structure. The coil embedded FBG sensor performance is validated by conventional TC sensors and is shown to have a strong potential to provide a flexible and EMI immune hot spot thermal monitoring solution that delivers improved fidelity information on the coil thermal conditions.

\section{REFERENCES}

[1] P.J. Tavner, "Review of condition monitoring of rotating electrical machines," in Electric Power Applications, IET, pp.215-47, July 2008.

[2] C.J. Crabtree, S. Djurovic, P.J. Tavner and A.C. Smith, "Condition monitoring of a wind turbine DFIG by current or power analysis," in Power Electronics, Machines and Drives (PEMD 2010), 5th IET International Conference on , vol., no., pp.1-6, 19-21 April 2010.

[3] S. Djurovic, D. Vilchis-Rodriguez, and A.C., Smith, "Investigation of wound rotor induction machine vibration signal under stator electrical fault conditions," The IET Journal of Engineering, pp. 1-11, May 2014.

[4] S. Grubic, J.M Aller, Lu. Bin and T.G Habetler, "A Survey on testing and monitoring methods for stator insulation systems of low-voltage induction machines focusing on turn insulation problems," in Industrial Electronics, IEEE Transactions on , vol.55/12, pp.4127-36, Dec. 2008.

[5] P. Tavner, LI Ran and J. Penman, "Condition monitoring of rotating electrical machines," IET Power and Energy Series, 2008.
[6] A. Siddique and B. Singh, "A review of stator fault monitoring techniques of induction motors," Energy conversion, IEEE Transactions on 20.1 (2005): 106-114.

[7] L. Hoffmann, MS. Müller, S. Krämer, M. Giebel, G. Schwotzer, and T. Wieduwilt, "Applications of fibre optic temperature measurement." Proc. Estonian Acad. Sci. Eng 13, no. 4 (2007): 363-378.

[8] C. Martelli, E. Silva, K. Souza, F. Mezzadri, J. Somenzi, M. Crespin, H.J. Kalinowski, and J.C. Silva, "Temperature sensing in a $175 \mathrm{MW}$ power generator," Proc. SPIE 8421, OFS2012.

[9] K. Sousa, A. Hafner, M Crespim, V. Oliveira, H. Kalinoski and J. Silva, "Fiber Bragg grating sensing applications in temperature monitoring of three-phase induction motors," Microwave \& Optoelectronics Conference (IMOC), 2011 SBMO/IEEE, 2011.

[10] D. Vilchis-Rodriguez, S. Djurovic, P. Kung, M.I Comanici, and A.C Smith, "Investigation of induction generator wide band vibration monitoring using fibre Bragg grating accelerometers," in Electrical Machines (ICEM), 2014 International Conference on , vol., no., pp.1772-1778, 2-5 Sept. 2014.

[11] M. Willsch, T. Bosselmann, M. Villnow and W. Ecke, "Fiber optical sensor trends in the energy field," Proc. SPIE 8421, OFS2012 22nd International Conference on Optical Fiber Sensors, 2012.

[12] A. D. Kersey, M. A. Davis, H. J. Patrick, M. LeBlanc, K. P. Koo, C. G. Askins, M. A. Putnam, and E. J. Friebele, "Fiber grating sensors." Journal of lightwave technology 15, no. 8 (1997): 1442-1463.

[13] N. Theune, M. Willsch, P. Krammer, T. Bosselmann, J. Kaiser . "Investigation of stator coil and lead temperatures on high voltage inside large power generators via use of fiber Bragg gratings." Sensors, 2002. Proceedings of IEEE. Vol. 2. IEEE, 2002.

[14] Wang, Peng, H. Zhao. "Quasi-distributed temperature measurement for stator bars in large generator via use of Fiber Bragg Gratings." Strategic Technology (IFOST), 2011 6th Int. Forum on, IEEE, 2011.

[15] Willsch, M., T. Bosselmann, and M. Villnow. "Fiber optic sensor solutions for increase of efficiency and availability of electric power generators." (EWOFS'10) Fourth European Workshop on Optical Fibre Sensors. International Society for Optics and Photonics, 2010.

[16] A. Mohammed, S. Djurovic, 'Evaluation of Fiber-optic Sensing Performance for Embedded Thermal Monitoring of Electric Machinery Wound Components,' IEEE MECO 2016, pp.1-4, Montenegro, 2016.

[17] IEEE Standard Test Procedure for Evaluation of Systems of Insulating Materials for Random-Wound AC Electric Machinery," in ANSI C50.32-1976 and IEEE Std 117-1974.

[18] Rao, Yun-Jiang, "In-fibre Bragg grating sensors," Measurement science and technology 8.4 (1997): 355.

[19] M. Reddy, S. Kamineni, and V. Rao Pachava, "Characterization of encapsulating materials for fiber bragg grating-based temperature sensors." Fiber and Integrated Optics 33, no. 4 (2014): 325-335.

[20] A.D. Kersey, M.A. Davis, H.J. Patrick, M. Leblane. "Fiber grating sensors." Journal of lightwave technology 15.8 (1997): 1442-1463.

[21] https://www.smartfibres.com/FBG-interrogators.

[22] D. Barrera, V. Finazzi, J. Villatoro, "Packaged optical sensors based on regenerated fiber Bragg gratings for high temperature applications." Sensors Journal, IEEE 12.1 (2012): 107-112.

\section{BIOGRAPHIES}

Anees Mohammed received the MSc degree in Electrical Power Engineering from University of Newcastle, Newcastle upon Tyne, UK, in 2010. He is currently pursuing the PhD degree in Electrical and Electronic Engineering at University of Manchester, Manchester, UK.

His employment experience includes 4 years as Assistant Lecturer at Benghazi University, Benghazi, Libya. His research interests are in electrical machines, drives and condition monitoring.

Siniša Djurović recieved his Dipl. Ing. degree from University of Montenegro in 2002 and his Ph.D. degree from University of Manchester in 2007. Dr. Djurović is currently a Lecturer in the School of Electrical and Electronic Engineering at The University of Manchester, UK. His research interests are in the area of modelling, design, application and condition monitoring of electrical machines and drives.

Alexander C. Smith received the B.Sc.Eng. and Ph.D. degrees from Aberdeen University, Aberdeen, U.K, in 1977 and 1980. Since 2000, he has been with The University of Manchester as Professor of Electrical Machines in the School of Electrical and Electronic Engineering. He is the Director of the Rolls-Royce University Technology Centre on Electrical Systems for Extreme Environments, Fellow of the IET and Editor-in-Chief of the IET journal Electrical Systems in Transportation. His research interests include design and modelling of motors, generators, and drives. 